JOEAI (Journal of Education and Instruction)

Volume 2, Nomor 1, Juni 2019

e-ISSN : 2614-8617

p-ISSN : 2620-7346

DOI : https://doi.org/10.31539/joeai.v2i1.614

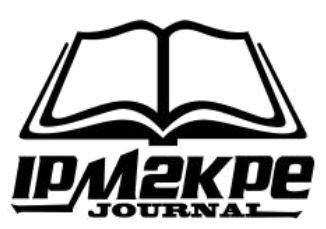

\title{
PROSES KOMUNIKASI INSTRUKSIONAL DALAM PEMBELAJARAN VOKASIONAL
}

\author{
Robeet Thadi \\ Institut Agama Islam Negeri Bengkulu \\ robeet@iainbengkulu.ac.id
}

\begin{abstract}
ABSTRAK
Tujuan penelitian ini adalah untuk melihat bagaimana proses komunikasi instruksional dalam pembelajaran vokasional di SMKN 1 Kota Bengkulu. Jenis penelitian adalah penelitian kualitatif dengan tradisi interaksionisme simbolik. Jadi, dengan metode ini peneliti memperoleh gambaran penelitian berdasarkan pengalaman subjek itu sendiri. Teknik pengumpulan data yang digunakan adalah observasi dan wawancara mendalam. Teknik analisis data menggunakan analisis data kualitatif. Hasil penelitian ini adalah komunikasi instruksional yang diterapkan dalam mengajar siswa vokasional adalah komunikasi secara verbal dan non verbal. Komunikasi verbal berupa kata-kata yang sederhana. Komunikasi non verbal yang dilakukan berupa gerakan tubuh. Selain itu, juga ditemui adanya komunikasi interpersonal. Simpulan, proses komunikasi instruksional yang diterapkan dalam mengajar siswa vokasional di SMKN 1 Kota Bengkulu adalah komunikasi secara verbal dan non verbal.
\end{abstract}

Kata Kunci: Komunikasi Instruksional, Pembelajaran, Vokasional.

\begin{abstract}
The purpose of this study was to see how the instructional communication process in vocational learning in SMK 1 Kota Bengkulu. This type of research is qualitative research with a tradition of symbolic interactionism. So, with this method the researcher obtains a description of the research based on the experience of the subject itself. Data collection techniques used were observation and in-depth interviews. The data analysis technique uses qualitative data analysis. The results of this study are instructional communication applied in teaching vocational students is verbal and non verbal communication. Verbal communication in the form of simple words. Non-verbal communication is carried out in the form of body movements. In addition, interpersonal communication was also found. Conclusion, the instructional communication process applied in teaching vocational students at SMKN 1 Kota Bengkulu is verbal and non verbal communication.
\end{abstract}

Keywords: Instructional, Learning, Vocational Communication. 


\section{PENDAHULUAN}

Manusia tidak bisa tidak berkomunikasi, komunikasi merupakan hal mendasar dalam kehidupan manusia. Dalam segala proses interaksi dengan orang lain dimana komunikasi untuk saling tukar informasi dan ekspresi diri. Komunikasi adalah hubungan kontak antarmanusia baik itu individu maupun kelompok. Dengan berkomunikasi manusia melakukan suatu hubungan karena manusia adalah makhluk sosial yang tidak dapat hidup sendiri melainkan membutuhkan satu sama lainnya (Tasmara, 1997).

Komunikasi merupakan instrumen penting yang selalu dilakukan manusia dalam kehidupannya, begitupun dalam dunia pendidikan. Dalam dunia pendidikan, komunikasi adalah cara seorang pendidik dalam menyampaikan sebuah materi pelajaran kepada peserta didik (Aziz, 2017). Dikarenakan setiap peserta didik adalah seorang pribadi yang berbeda, maka cara berkomunikasi dengan mereka pun berbeda.Tentunya pendidik akan memikirkan cara untuk menyampaikan materi belajar kepada peserta didik. Cara yang digunakan berupa komunikasi yang harus ada hubungan timbal balik diantara keduanya.

Sesungguhnya komunikasi pendidikan memiliki posisi penting baik dalam konteks kajian di ranah keilmuan komunikasi dan keilmuan pendidikan maupun sebagai skill praktis yang dapat menunjang proses pendidikan itu sendiri. Dalam proses pembelajaran, kajian komunikasi pendidikan lebih pada proses instruksional. Komunikasi instruksional merupakan bagian kecil dari komunikasi pendidikan. Komunikasi instruksional merupakan komunikasi yang dipola dan dirancang secara khusus untuk mengubah perilaku sasaran dalam komunitas tertentu ke arah yang lebih baik.

Komunikasi instruksional merupakan komunikasi dalam pengajaran di kelas, guru sebagai komunikator, siswa sebagai komunikan, sedangkan pesan yang akan disampaikan adalah materi yang akan diajarkan di dalam kelas. Orientasi komunikasi instruksional lebih banyak kepada orang-orang yang belajar, bukan kepada pihak yang mengajar. Proses komunikasi instruksional diciptakan secara wajar, akrab, dan terbuka dengan ditunjang oleh faktor-faktor pendukung lainnya, baik sebagai sarana maupun sebagai fasilitas lain, dengan tujuan supaya mempunyai efek perubahan perilaku pada pihak sasaran.

Guru bertindak sebagai pelaksana komunikasi instruksional (komunikator) dan siswa sebagai penerimanya (komunikan). Komunikasi ini berlangsung melalui proses pembelajaran. Proses pembelajaran memiliki beberapa komponen yaitu siswa, guru, isi pelajaran, metode mengajar, media pembelajaran dan evaluasi.

Dalam proses pembelajaran, komunikasi intruksional merupakan salah satu faktor yang menentukan keberhasilan dalam suatu pembelajaran. Sebagaimana dikemukakan oleh Ary H. Gunawan instruksional dalam pembelajaran meliputi 1) Apa yang akan diajarkan, 2) Bagaimana cara mengajarkannya, dan 3) Bagaimana menilai bahwa tujuannya telah tercapai. 
Jelaslah bahwa desain intruksional berkaitan dengan bagaimana seorang guru atau tutor dalam menyampaikan materi yang akan diberikan pada siswa dan bagaimana melakukan penilaian atau evaluasi terhadap keberhasilan siswa dalam menyerap materi pembelajaran (Gunawan, 2010).

Dalam penelitian ini, komunikasi intruksional yang disoroti adalah komunikasi intruksional guru dalam mengajar pada lembaga pendidikan vokasional. Pendidikan vokasional merupakan proses pembelajaran yang mempersiapkan peserta didik untuk memasuki lapangan kerja setelah menyelesaikan studinya, sebuah kondisi nyata yang dibentuk untuk mewujudkan pengetahuan yang sesuai dengan nilai-nilai yang diharapkan dalam bekerja.

Pendidikan Sekolah Menengah Kejuruan (SMK) sebagai pendidikan vokasional tingkat menengah, memiliki peran besar dalam merencanakan dan menciptakan SDM yang profesional dan produktif. Pendidikan di Sekolah Menengah Kejuruan (SMK) bertujuan untuk meningkatkan pengetahuan dan keterampilan siswa dalam rangka menyiapkan mereka sebagai tenaga kerja tingkat menengah.

Belakangan ini nama SMK sangat melejit, bersamaan dengan meninggkatnya mutu pendidikan jurusan SMK. Baiknya pendidikan yang dibutuhkan Murid/i SMK adalah pendidikan yang berkarakter namun tidak membatasi ruang gerak kebebasan murid dalam berkreasi dan berkompetisi antar murid. Cara mengajar gurupun berpengaruh pada belajar murid. Apalagi belakangan ini ada perubahan kurikulum baru dengan waktu belajar yang cukup lama. Jika cara ajar guru masih pasif, tidak menyenangkan, dan cenderung kaku bagaimana peserta didik bisa menerima dan menyukai pelajaran bila dengan pengajarnya pun mereka sudah tak begitu suka dan cenderung benci. Dalam mendidik guru harus menjadikan murid sebagai sahabat, kenali karakter mereka maka dari situ lah akan terjalin hubungan belajar mengajar yang baik dan interaktif.

SMK Negeri 1 Kota Bengkulu merupakan SMK Kelompok pendidikan vokasi unggulan di kota Bengkulu, ini terbukti dari semua jurusan yang ada terakreditasi 'A' yakni sertifikasi internasional (ISO 9001:2008) sebagai manajemen of vocational school yakni Jurusan Akuntansi, Administrasi Perkantoran, Pemasaran, Usaha Perjalanan Wisata, Multimedia dan Teknik Komupter \& Jaringan.

Mengingat animo masyarakat untuk memasuki SMK meningkat dari tahun ketahun, demi menjaga layanan, kualitas dan output. Di mana SMK sebagai pendidikan vokasional untuk menciptakan alumni siap kerja. Dalam pembelajaran program vokasional tentunya memiliki proses komunikasi yang digunakan dalam interaksi komunikasi antara guru dan murid, dimana komunikasi ditujukan pada aspek-aspek operasionalisasi dalam proses pembelajaran atau yang disebut dengan komunikasi instruksional, terutama aspek membelajarkan sasaran. Situasi, kondisi, lingkungan, metode, dan termasuk "bahasa" yang digunakan oleh guru 
sebagai komunikator sengaja dipersiapkan secara khusus untuk memberikan materi-materi pendidikan vokasi agar dapat dipahami murid. Dalam Proses pembelajaran, guru memperhatikan tingkah murid mulai dari yang rajin dan yang sama sekali tidak memperhatikan pelajaran yang sedang di terangkan. Karena setiap guru dibekali ilmu psikologis guna mengetahui karakter murid mulai dari cara dia berkomunikasi dengan guru dan cara dia menjawab pertanyaan yang diberikan guru. Setiap guru yang masuk untuk mengajar memiliki metode dan cara mengajar yang berbeda-beda serta penerapan aturan yang berbeda. SMKN 1 Kota Bengkulu memiliki visi untuk menjadi lembaga pendidikan yang mampu menghasilkan mutu lulusan yang terampil dibidang manajemen of vocational school, mandiri, berwawasan global dan berakhlaq mulia.

Dalam hal ini tentunya guru harus dapat menggunakan proses komunikasi instruksional yang efektif dalam pembelajaran kepada muridnya agar dapat memahami materi pelajaran yang dikomunikasi guru hingga tercapainya tujuan dari komunikasi yang dilakukan guru dalam proses pembelajaran. Sesuai dengan pemaparan penulis diatas maka penelitian ini mengkaji tentang "Proses Komunikasi Instruksional Dalam Pembelajaran Vokasional di SMKN 1 Kota Bengkulu."

\section{METODE PENELITIAN}

Pendekatan yang digunakan dalam penelitian ini adalah pendekatan kualitatif dengan tradisi interaksionisme simbolik, yaitu suatu metode untuk memaparkan serta menjelaskan kegiatan atau objek yang diteliti yang berkaitan dengan pengkajian fenomena secara lebih rinci atau membedakannya dengan fenomena yang lain (Denzin, K Norman \& Lincoln, 2009). Data yang dihasilkan dari deksriptif kualitatif berupa data deskriptif. Data deskriptif merupakan data yang berupa kata-kata, gambar dan bukan angka-angka (Moleong, 2005).

Data lapangan diperoleh dengan cara: 1). Observasi terhadap komunikasi instruksional dilakukan dengan mengamati proses pembelajaran yang sedang berlangsung di SMKN 1 Kota Bengkulu, baik guru sebagai komunikator komunikasi instruksional maupun siswa sebagai komunikannya. 2). Wawancara mendalam kepada informan yang diambil dari guru dan siswa yang dijadikan sebagai obsever dalam kegiaan pembelajaran. Wawancara juga dilakukan dengan pihak pimpinan sekolah untuk.

Informan dalam penelitian ini diambil dari guru dan siswa yang memiliki kapabilitas dan kompeten untuk memberikan data secara maksimal. Sedangkan pengambilan sampelnya dengan teknik purposif sampling (peneliti memilih informan secara bertujuan). Teknik analisis data yang digunakan adalah model analisa interaktif yang dikembangkan oleh Miles dan Hubermann yang terdiri:1) Pengumpulan data; 2) Reduksi data; 3) Penyajian data 4) Penarikan simpulan dan verifikasi. 


\section{HASIL DAN PEMBAHASAN}

Penelitian ini merupakan upaya untuk mengkonstruksi proses komunikasi instruksional dalam pembelajaran vokasional. Penelitian yang bertradisi interaksionisme simbolik mengedepankan bagaimana pertukaran simbol dari ineraksi yang terjalan antara guru sebagai komunikator dan siswa sebagai komunikan dalam proses pengajaran.

Hasil penelitian ini untuk melihat bagaimana proses komunikasi instruksional dalam pembelajaran vokasional di SMKN 1 Kota Bengkulu melalui pengamatan langsung dan wawancara kepada beberapa informan penelitian, sehingga diperoleh fakta-fakta hasil di lapangan mengenai komunikasi intruksional, mengingat model pembelajaran vokasional agak berbeda dengan model pembelajaran di sekolah umum diperlukan kreativitas guru dalam berinteraksi dengan siswa. Untuk itu diperlukan komunikasi intruksional yang membantu mengarahkan pemahaman guru terhadap pentingnya kreativitas dalam membelajaran, komunikasi intruksional merupakan sebuah proses dan kegiatan komunikasi yang dirancang secara khusus yang bertujuan untuk meningkatkan nilai.

Secara konseptual proses komunikasi merupakan gambaran tentang bagaimana komunikasi berlangsung antara pihak-pihak yang terlibat dalam aktivitas komunikasi. Dalam pembelajaran, proses komunikasi intruksional merupakan baik atau buruknya situasi cara mengajar guru, sikap guru, kurikulum,alat bantu mengajar, ruang kelas dan lain sebagainya untuk meningkatkan pencapaian hasil (Syah, 2011). Beberapa proses intruksional pada umumnya bergantung kepada cara guru menyampaikan pesan kepada siswasiswanya yang memilik banyak perbedaan karakteristik dengan program yang diberikan dan yang berpengaruh dengan lingkungan sekitar.

Pada umumnya untuk pencapaian hasil proses intruksional itu bergantung pada faktor-faktor yang meliputi: pertama, Karakteristik siswa. Siswa di sekolah vokasi atau kejuruan merupakan siswa yang secara kompetensi sudah memiliki skill dasar dalam bidang keahlian tertentu. Dalam proses komunikasi intruksionalnya untuk siswa yang berasal dari jurusan berbeda, membutuhkan interkasi komunikasi verbal dan nonverbal yang berbeda dan harus ada penekan tertentu dalam penyampaian materi oleh guru kepada siswa melalui pesan nonverbal. 2) karakteristik guru merupakn guru yang ramah, tegas dan sopan terhadap siswa agar siswa dapat meniru sikap atau tutur bahasa guru yang mengajar. Setiap dalam kelas guru yang mengajar selalu menjaga tutur kata kepada semua siswa. 3). Interaksi dan metode merupakan komunikasi dua arah yang dilakukan guru ke siswa maupun siswa ke guru. Para guru melakukan interaksi dengan siswanya melalui komunikasi yang jelas agar pesan yang disampaikan tercapai. Seperti melakukan tanya jawab tentunya guru yang menjawab memberikan pejelasan yang benar dan jelas. 4) Fasilitas fisik merupakan segala sesuatu yang berupa benda atau yang dapat dibedakan, yang 
mempunyai peranan dalam memudahkan dan memperlancar suatu kegiatan. Fasilitas fisik yang ada di SMKN 1 Kota Bengkulu d iruang kelas berupa peralatan parktikum, meja, lemari, papan tulis ,spidol, penghapus, air minum, karpet dan kotak infak. 5) lingkungan sekitar. Lingkungan sangat berpengaruh terhadap siswa tentunya karena lingkungan yang buruk akan merubah siswa tersebut malas belajar sesuai dengan zaman sekarang yang teknologi sudah mempengaruhi sikap manusianya. Namun, jika lingkungan sekitarnya yang baik maka akan berpengaruh baik pula untuk siswa tersebut.

Proses komunikasi intruksional ini melibatkan simbol-simbol nonverbal seperti gerakan mulut, dari guru yang mengucapkan ayat perayat alquran dan intonasi suara yang jelas agar siswa dapat membenarkan bacaan alqurannya. Didalam proses belajar para guru harus bisa membaca situasi kondisi siswa atau kelas agar siswa bisa menerima pesan yang disampaikan guru dengan cara salah satunya memberikan motivasi-motivasi pentingnya membaca dan menghafal alquran agar semangat menghafal. kesadaran manusia untuk membaca dan menghafal alquran tergantung dari motivasi diri masing-masing. Jika sadar pentingnya membaca dan menghafal alquran maka proses tersebut akan terlaksana dan target akan tercapai. Para guru tidak hanya memberikan motivasi kepada siswa dalam proses komunikasinya namun guru yang mengajar sesekali memberikan games hafalan. Ini diterapkan agar proses komunikasi berjalan lancar, dan siswa tidak merasa bosan dalam proses pembelajaran. Proses ini biasa digunakan oleh siswa anak-anak. Proses komunikasi intruksional yang digunakan ustad ini tentunya diiringi dengan siswa yang bersungguh-sunguh, mau berdoa dan istiqomah. Istiqomah merupakan target yang dicapai agar mengetahui waktu yang cocok untuk menambah hafalan contohnya menghafal ditempat yang sepi atau menghafal sebelum tidur karena dengan kita bisa mengetahui waktu yang cocok kita bisa lebih fokus dan cepat menghafal.

Pada proses pembelajaran, hal penting yang harus diperhatikan tidak hanya metode mengajar namun juga media pembelajaran. Media yang digunakan di SMKN 1 Kota ini yaitu berupa media cetak seperti buku pegangan/modul, media video, alat peraga pratikum. Buku pegangan/modul yang diberikan ke setiap siswa untuk mengaplikasikan instruksi yang diberikan oleh guru. Dengan adanya buku pegangan/modul, siswa akan terlatih untuk membaca dan memperhatikan setiap bacaan yang ada di dalam buku. Namun untuk media video berupa pemutaran film dan video dalam proses belajar mengajar dapat menjelaskan banyak hal tentang teknis aplikasi vokasi jurusan yang ada. Film dan video dapat menyajikan informasi, memaparkan proses, menjelaskan konsep-konsep yang rumit, mengajarkan keterampilan, mempersingkat atau memperpanjang waktu, dan mempengaruhi sikap.

Hasil penelitian ini adalah komunikasi instruksional yang diterapkan dalam mengajar siswa vokasional adalah komunikasi secara verbal dan non verbal. Komunikasi verbal berupa kata-kata yang sederhana. Komunikasi non 
verbal yang dilakukan berupa gerakan tubuh. Selain itu, juga ditemui adanya komunikasi interpersonal. Jadi, guru mengajar secara individual. Kegiatan instruksional dimulai dengan sesi pendahuluan, kemudian dilanjutkan dengan penyampaian materi pelajaran. Kemudian, kegiatan instruksional diakhiri dengan kegiatan evaluasi, dimana guru melakukan penilaian terhadap siswa. Proses instruksional, yang digunakan di terdiri dari berbagai macam proses seperti proses komunikasi primer seperti berbicara langsung tanpa menggunakan media, dan proses komunikasi sekunder dengan menggunakan media kedua setelah kata-kata untuk menyampaikan materi kepada siswa.

\section{SIMPULAN}

Berdasarkan pembahasan hasil penelitian penelitian ini menyimpulkan bahwa proses komunikasi instruksional yang diterapkan dalam mengajar siswa vokasional di SMKN 1 Kota Bengkulu adalah komunikasi secara verbal dan non verbal. Komunikasi verbal berupa kata-kata yang sederhana. Komunikasi non verbal yang dilakukan berupa gerakan tubuh. Proses instruksional, yang digunakan di terdiri dari berbagai macam proses seperti proses komunikasi primer seperti berbicara langsung tanpa menggunakan media, dan proses komunikasi sekunder dengan menggunakan media kedua setelah kata-kata untuk menyampaikan materi kepada siswa.

\section{DAFTAR PUSTAKA}

Angraini, H. W. (2016). Komunikasi Instruksional Guru dalam Meningkatkan Minat Membaca dan Menghafal Alquran di Maqdis Kota Duri Kecamatan Mandau Kabupaten Bengkalis. JOM FISIP, 3(2), 1-15.

Aziz, A. (2017). Komunikasi pendidik dan peserta didik dalam pendidikan islam. Jurnal Mediakita, Vol.1(2), 173-184.

Denzin, K Norman \& Lincoln, Y. S. (2009). Hanbook of Qualitative Research. (Dariyanto, Ed.). Yogyakarta: Pustaka Pelajar.

Devito, J. A. (1997). Komunikasi Antar Manusia Kuliah Dasar. (M. Agus, Ed.) (Alih Bahas). Jakarta: Professional Book.

Gunawan, A. H. (2010). Sosiologi Pendidikan: Suatu Analisis Sosiologi Tentang Pelbagai Problem Pendidikan. Jakarta: Rineka Cipta.

Moleong, L. J. (2005). Metodologi Penelitian Kualitatif (Cet-20). Bandung: Remaja Rosda Karya.

Mulyana, D. (2008). Metode Penelitian Kaulitatif: Paradigma Baru Ilmu Komunikasi dan Ilmu Sosial Lainnya. Bandung: Remaja Rosdakarya.

Sutirman. (2012). Komunikasi Efektif dalam Pembelajaran. Retrieved from http://tirman.wordpress.com/komunikasi-efektif-dalam-pembelajaran/.[20 Januari]

Syah, M. (2011). Psikologi Belajar. Jakarta: Rajawali Press.

Tasmara, T. (1997). Komunikasi Dakwah (Cet. II). Jakarta: Gaga Media Pratama.

Yusup, P. M. (2010). Komunikasi Instruksional: Teori dan Praktik. Jakarta: Bumi Aksara. 